\title{
Russian summer hopes dwarf doubts
}

\author{
Russian science seems to have survived the winter and the first phase of price liberalization, but there is a long \\ way to go before it can compete on equal terms.
}

Moscow. The difference between summer and winter here is not just the external temperature, but people's frame of mind. Especially towards the end of the long winter, spirits are at nadir. The return of a little natural warmth has each year liberated the natural optimism of those who live in this still-isolated part of the world. That, no doubt, is part of the explanation of the relative cheerfulness with which many research people now regard the future.

But there is also some substance in the change of mood since, say, last December. Seemingly insuperable problems have often been overcome by ingenuity and a little luck. The exodus of able and mostly senior people, for example, has not brought all the catastrophic consequences predicted.

The Moscow Institute of Molecular Genetics illustrates what has happened. Out of a total of 200 scientists and 150 students, no fewer than 40 people have left, of whom 36 previously occupied senior research positions. Many of the departed have finished up in US universities. Of necessity, these departures often decapitated successful research groups, leaving students and others leaderless at short notice or none.

Opinions are sharply divided on the manner in which some have left. Sometimes people have gone to "visit relatives" in the United States, and have allowed their intention not to return to be inferred only from the length of their absence. Some vigorously condemn this practice, but Dr Evgenii Sverdlov, the director of the institute, has resolved instead on a more pragmatic policy. "I want to understand what is in their minds", he says. So the departed are kept on the institute's books and even paid a portion of their salaries. "We cannot afford to make enemies", says Sverdlov.

Some also argue that the way in which junior colleagues, even students, have been compelled to take more responsibility on their shoulders is a blessing in disguise. All too often in the past, heads of laboratories regarded their subordinates as just that. Now there are bright-eyed students who play a part in the planning of research.

Even so, nobody can be sure that the supply of these young men and women will persist. A graduate student's life, never easy, is now one of hardship. The standard stipend, the equivalent of a few dollars a month, is plainly insufficient. Some students get by only because they live with their parents or are otherwise subsidized by them. At the elite schools, such as the Moscow Physical Technical Institute, the NATURE · VOL 357 • 4 JUNE 1992 undergraduate course lasts for six years.

The chances that these depressing prospects will feed back onto the age-groups feeding the better schools are, nevertheless, not high. One of Russia's most enduring assets may be the passion of those with bourgeois inclinations to see their sons and daughters educated well. Respect for intellectual achievement has survived the past 70 years well - too well, perhaps, for the health of tottering industry.

Meanwhile, it seems inevitable that basic research will need external help for some years to come. As things are, the most successful research groups are those that have established collaborations in the West. The benefits are huge: reagents otherwise unobtainable, pieces of equipment that could not be found locally, spare parts for machines that could not otherwise be used and occasional overseas trips. There is also, of course, a certain standing among competing groups that derives from such a collaboration. What stands out from a handful of working collaborations is that potential partners in the West are not driven by simple altruism. Partnerships emerge only when the Russian side can make a unique contribution. This period is flushing out islands of skill that make it seem worthwhile elsewhere to put up with the hassle of the still dreadful communications.

This is also the basis of the significant (if small) deals between companies in the West and Russian laboratories as different as the Kurchatov Institute in Moscow and the Electron Optics Institute at Omsk (in the southern Urals). Russian groups have contracted to carry out research in fields as different as plasma physics and fibre optics for the US Department of Energy and AT\&T respectively. Monsanto and Sun Microsystems were even earlier in the field. Apart from the equipment and the modest travel these arrangements bring, these contracts pay salaries in US dollars. The going rate seems to have settled down at about $\$ 60$ a month $-7,500$ rubles at the commercial rate of exchange.

Just what these numbers mean is a kind of mystery. At the end of last year, laboratories were talking of salaries of $1,800 \mathrm{ru}$ bles a month for senior people, essentially a doubling in four years. But since then, prices of some (not all) commodities have been 'liberalized'. In some areas, such as foodstuffs, some prices have increased by huge factors - bread, for example, by a factor of 50 or so - and, now, some have even begun to fall, as market economists say they should. No doubt they would fall faster, or rise less quickly, if only Russia's chronically inefficient distribution system was reformed.

The worry is that there is still worse to come. Although the cost of a tankful of gasoline (petrol) is now ten per cent of a decent salary, the price is still less than that in the United States. (The Russian government is resisting demands by the International Monetary Fund that gasoline prices should rise to world levels as a condition for financial support.) Whole other areas of the economy, housing for example, remain an odd mixture of liberalization and the opposite. (People are encouraged to buy their own apartments, but cannot afford them, let alone the cost of maintenance.)

The publications part of the scientific enterprise has suffered most immediately from the economic upheavals chiefly because the price of paper has become realistic almost overnight. The editor of one science magazine, asked why he published so few book reviews, said, "There are no books". The publishing houses once owned by the state have been required to operate without losing money; many are doing that by hiving off the profitable parts of their businesses to collectives of their own employees.

Journals are still subsidized by the Russian Academy of Sciences, but, increasingly often, individual institutes at which particular journals are edited are making translation deals with publishers in the West, hoping that modest royalties paid in dollars will more than cover their ruble costs.

General circulation magazines have been much harder hit. The excellent general magazine whose Russian title translates as Chemistry and Life is a victim first of glasnost (which gave people such interesting other things to read that circulation began falling sharply from 300,000) and then of paper prices. (Circulation is now down to 120,000 .) The magazine gets by with the help of a subsidy of 500,000 rubles a month from the Ministry of Information and Press.

Priroda (which means "Nature"), another academy magazine aimed at an audience such as that of Scientific American, lives more from hand to mouth. This journal, Nature, is doing what it can to help by trying to sell advertisements in the West, and plans to produce, the October issue.

Whether there will in due course be a market for these magazines, as for many other Russian products, is strictly conjectural. Perhaps because it is now summer, the optimists are in the ascendant.

John Maddox 